\title{
Implementation of the Glucommander Method of Adjusting Insulin Infusions in Critically III Patients
}

\author{
Sharon Yamashita, Emily Ng, Frank Brommecker, Jay Silverberg, and Neill K J Adhikari
}

\begin{abstract}
Background: Intensive glycemic control has been associated with reduced morbidity and mortality in critically ill patients. Web-based, patientspecific insulin nomograms may facilitate improved glucose control.

Objective: To compare 2 algorithms for individualizing insulin infusion therapy (a web-based system [Glucommander method] and a standard paper-based nomogram) in a cardiovascular surgery intensive care unit (ICU).
\end{abstract}

Methods: In this prospective, before-after cohort study, measures of glycemic control for 50 patients receiving insulin according to the Glucommander system were compared with a control group $(n=50)$ who received insulin according to the standard paper-based nomogram used in the cardiovascular surgery ICU.

Results: There was no significant difference between the 2 groups with respect to time to target blood glucose $(5.1-8.0 \mathrm{mmol} / \mathrm{L})$, percentage of time within the target range, or mean amplitude of glucose excursion. Patients in the intervention group spent less time above the target range $(p=0.007)$ and more time below the target range $(p<0.001)$, and the mean glucose was lower in this group compared with the control group ( 7.9 versus $8.6 \mathrm{mmol} / \mathrm{L}, p=0.002$ ). The percentage of blood glucose measurements below $4 \mathrm{mmol} / \mathrm{L}$ was higher in the intervention group than in the control group $(3.7 \%$ versus $1.4 \%, p=0.003)$. Satisfaction surveys revealed that the program was well accepted by the nursing staff in the cardiovascular surgery ICU.

Conclusions: A web-based insulin nomogram was an easy-to-use instrument for achieving tighter glucose control for patients in the cardiovascular surgery ICU. Use of the Glucommander system led to lower mean blood glucose but an increase in episodes of hypoglycemia.

Key words: tight glycemic control, critically ill patients

\section{RÉSUMÉ}

Contexte : La régulation intensive de la glycémie a été associée à une réduction de la morbidité et de la mortalité chez les patients gravement malades. Des nomogrammes personnalisés d'ajustement posologique de l'insuline accessibles sur le Web pourraient faciliter la régulation de la glycémie.

Objectif : Comparer deux algorithmes de personnalisation de la perfusion d'insuline (nomogramme en ligne [méthode Glucommander] et nomogramme standard sur papier) dans une unité de soins intensifs (USI) chirurgicaux cardiovasculaires.

Méthodes : Dans cette étude prospective de cohortes avant-après, on a comparé les mesures de la régulation glycémique chez 50 patients dont le débit de perfusion d'insuline a été adapté au moyen du système Glucommander à ceux du groupe témoin $(n=50)$ qui ont reçu l'insuline selon le nomogramme standard sur papier, à l'USI chirurgicaux cardiovasculaires.

Résultats : On n'a observé aucune différence significative entre les deux groupes pour ce qui est du temps d'obtention des valeurs glycémiques cibles $(5,1$ à $8,0 \mathrm{mmol} / \mathrm{L})$, du pourcentage de temps où la glycémie est demeurée dans la plage des valeurs cibles et de l'amplitude moyenne de la variation des valeurs de la glycémie. Dans le groupe Glucommander, la glycémie est demeurée moins longtemps au-dessus de la plage des valeurs cibles $(p=0,007)$ et plus longtemps au-dessous de la plage des valeurs cibles $(p<0,001)$, et sa valeur moyenne était moins élevée que dans le groupe témoin $(7,9$ contre $8,6 \mathrm{mmol} / \mathrm{L}, p=0,002)$. Le pourcentage de mesures de la glycémie au-dessous de $4 \mathrm{mmol} / \mathrm{L}$ était plus élevé dans le groupe Glucommander que dans le groupe témoin (3,7 \% contre 1,4\%, $p=0,003)$. Des sondages sur la satisfaction ont révélé que le programme était bien accepté par le personnel infirmier de l'USI chirurgicaux cardiovasculaires.

Conclusions : Le nomogramme en ligne était facile à utiliser pour obtenir une régulation plus serrée de la glycémie chez les patients de l'USI chirurgicaux cardiovasculaires. Le recours au système Glucommander s'est traduit par des valeurs glycémiques moyennes moins élevées, mais par une augmentation des épisodes d'hypoglycémie.

Mots clés: régulation serrée de la glycémie, patients gravement malades

[Traduction par l'éditeur] 


\section{INTRODUCTION}

$\mathrm{H}$ yperglycemia occurs frequently in critically ill patients, even those without a history of diabetes mellitus, because of physiological, stress-induced disturbances in the integrated hormonal, cytokine, and counter-regulatory nervous system signals that influence glucose metabolic pathways. ${ }^{1}$ Historically, treatment of stress-induced hyperglycemia with exogenous insulin was considered necessary only for patients with known diabetes mellitus or when blood glucose levels were extremely elevated. More recently, a landmark randomized controlled trial (RCT) found that outcomes in a surgical intensive care unit (ICU) improved when the target blood glucose level was less than $6.1 \mathrm{mmol} / \mathrm{L}^{2}$ However, these results could not be replicated in other large RCTs in medical or mixed medical-surgical ICU settings, ${ }^{3-5}$ including the largest RCT addressing this issue to date..$^{5}$ In addition, the rates of severe hypoglycemia (blood glucose $<2.2 \mathrm{mmol} / \mathrm{L}$ ) were significantly higher among patients randomly assigned to the intensive insulin therapy arm in each of these studies. ${ }^{2-5}$ Therefore, although accumulated RCT evidence suggests that intensive insulin therapy targeting blood glucose levels below 6.1 $\mathrm{mmol} / \mathrm{L}$ does not reduce morbidity and mortality in critically ill patients, ${ }^{6}$ it is generally accepted that hyperglycemia (blood glucose $>10 \mathrm{mmol} / \mathrm{L}$ ) should be treated.

Given the available evidence, many institutions have implemented strategies to improve glycemic control using standardized paper-based, nurse-directed insulin nomograms that adjust rates of insulin infusion according to the current rate of infusion and the blood glucose reading. However, these nomograms usually do not take patient-specific blood glucose trends into consideration. Therefore, patients may oscillate between hypoglycemia and hyperglycemia.

In contrast, Glucommander ${ }^{7}$ is a computerized algorithm that incorporates the blood glucose level, the current infusion rate, and the patient's sensitivity to insulin to calculate any necessary change in insulin infusion rate. This algorithm has been shown to safely achieve near normoglycemia in hospital inpatients, with a lower incidence of hypoglycemia than reported in initial RCTs of intensive insulin therapy.

The current study was undertaken to test the hypothesis that the Glucommander algorithm would improve glycemic control, reduce hypoglycemia, and increase nursing satisfaction, relative to the existing paper-based insulin nomogram, in the cardiovascular surgical population at the authors' institution.

\section{METHODS}

\section{Setting, Patients, and Treatment Groups}

This prospective before-after cohort study was conducted in the 14-bed Cardiovascular Surgery ICU at Sunnybrook
Health Sciences Centre, a 1275-bed university-affiliated teaching hospital, from March to November 2007. All adult patients (18 years of age or older), with or without an established diagnosis of diabetes mellitus, who required infusion of insulin because of blood glucose levels above $8.1 \mathrm{mmol} / \mathrm{L}$, were eligible for enrolment in the study. Patients with a diagnosis of diabetic ketoacidosis or hyperosmotic nonketotic coma were excluded.

The control cohort consisted of 50 patients admitted to the Cardiovascular Surgery ICU in March and April 2007, whose insulin infusions were managed with the existing paperbased nomogram (see Appendix 1, available online at www.cjhp-online.ca/index.php/cjhp/issue/view/83/showToc). With this nomogram, infusion rates for regular human insulin are adjusted on the basis of the patient's current infusion rate and current blood glucose level, as measured at the bedside with a hospital-approved blood glucose meter (Precision QID, Abbott Laboratories Limited, Mississauga, Ontario). For all patients, insulin is initiated with a blood glucose-dependent bolus, followed by infusion of 2 units/h. Subsequent changes to the infusion rate are based on the current blood glucose level and do not take into account response to previous doses of insulin. The frequency of blood glucose measurements decreases over time as levels reach the target range $(5.1-8.0 \mathrm{mmol} / \mathrm{L})$ and insulin requirements stabilize. The insulin infusion is withheld when the blood glucose drops below $5.0 \mathrm{mmol} / \mathrm{L}$, and $50 \mathrm{~mL}$ of $50 \%$ dextrose in water (D50W) is administered IV when the blood glucose drops below $3.5 \mathrm{mmol} / \mathrm{L}$.

The original standardized insulin nomogram, with a target glucose range of $7.1-11.5 \mathrm{mmol} / \mathrm{L}$, was implemented in the Cardiovascular Surgery ICU in 2004 through a series of nursing in-service sessions. The nomogram was later revised to the current target range of $5.1-8 \mathrm{mmol} / \mathrm{L}$, and the revised version was introduced in June 2006.

The interventional cohort consisted of 50 patients admitted to the Cardiovascular Surgery ICU from May to November 2007. For these patients, insulin infusions were individualized according to the Glucommander computerized algorithm. A pharmacist with programming experience (F.B.) created a webbased interface (see Figure 1) that used the following formula (originally presented by Davidson and others ${ }^{7}$ ): insulin dose $($ units $/ \mathrm{h})=($ blood glucose -3.3$) \times$ multiplier, where the blood glucose is measured in millimoles per litre. According to this algorithm, the initial multiplier is set to 0.02 . For patients in the intervention group, no bolus doses of insulin were administered, and each patient was initiated on a different insulin infusion rate, based on the initial blood glucose level.

If the insulin dose delivered did not decrease the blood glucose by $25 \%$ by the time of the next reading, then the multiplier (also known as the "insulin sensitivity factor") was increased by 0.01 . If the blood glucose level was below the 


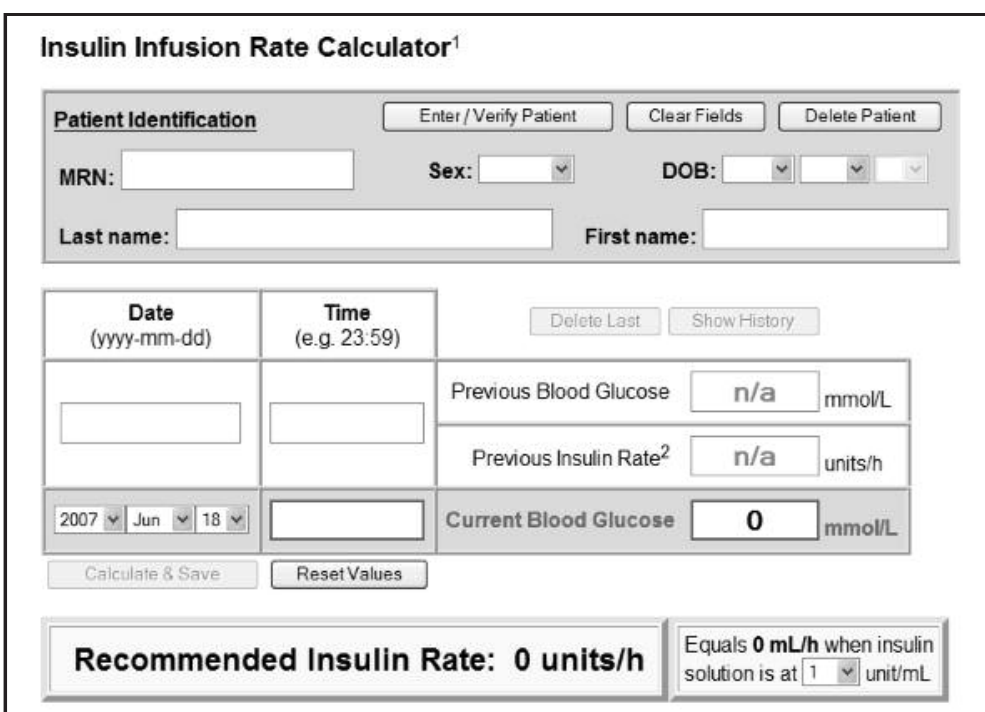

Figure 1. Appearance of the web-based interface for determining insulin dosing (based on the Glucommander method).

target range $(5.1-8 \mathrm{mmol} / \mathrm{L})$, the multiplier was decreased by 0.01 . If the blood glucose was within target, the multiplier was not changed. If the blood glucose dropped below $3.5 \mathrm{mmol} / \mathrm{L}$, the multiplier was decreased by 0.01 and the insulin drip was withheld. The amount of $\mathrm{D} 50 \mathrm{~W}$ to be administered was calculated according to the following formula: D50W $(\mathrm{mL})=$ $(5.6-$ blood glucose $) \times 0.4$. This formula assumes that in a normal-weight patient, $25 \mathrm{~g}$ of glucose will raise the blood glucose level by about $6.95 \mathrm{mmol} / \mathrm{L} .^{8}$

The frequency of blood glucose measurements was the same as that specified in the Cardiovascular Surgery ICU insulin nomogram (see Appendix 1). Nursing staff and team physicians in the Cardiovascular Surgery ICU were trained in the use of the Glucommander program through a series of group and one-on-one in-service sessions.

Nurses' feedback was elicited throughout the study period, and changes were made to the web-based user interface accordingly.

In both groups, termination of the insulin infusion occurred when the patient was discharged from the Cardiovascular Surgery ICU or earlier, at the discretion of the medical staff.

Patients in both groups did not receive enteral feeding in the immediate postoperative period. All patients who were not being fed at the time of insulin initiation received $10 \%$ dextrose in water $(\mathrm{D} 10 \mathrm{~W})$ at $25 \mathrm{~mL} / \mathrm{h}$ to prevent hypoglycemia.

\section{Data Collection}

Trained data abstracters (S.Y., E.N.) collected all data prospectively, from the time of enrolment until the end of the patient's stay in the Cardiovascular Surgery ICU or for a maximum of 7 days after the start of the insulin infusion. Baseline data included demographic characteristics (age, weight, sex), prior history of diabetes, blood glucose level on admission, and other information necessary to calculate the Acute Physiology and Chronic Health Evaluation (APACHE) II score," a measure of severity of illness. Several parameters relating to glycemic control were examined: mean time to achieve target blood glucose of 5.1-8.0 mmol/L, the first blood glucose value within the target range, the percentage of time that blood glucose measurements were within the target range, the mean blood glucose level, and the mean amplitude of glycemic excursion (a measure of diabetic instability that is calculated as the arithmetic mean of glycemic excursions exceeding 1 standard deviation of the mean, calculated for each successive 24-h period $\left.^{10}\right)$. Recent studies have suggested that measurement of glucose variability may be a more important predictor of outcome than mean blood glucose levels..$^{11,12}$

The number of episodes of hypoglycemia (blood glucose $<4.0 \mathrm{mmol} / \mathrm{L}$ ) and the number of times that the patient required an IV "rescue" dose of D50W because the blood glucose was less than $3.5 \mathrm{mmol} / \mathrm{L}$ were also recorded. Data on the daily caloric intake from dextrose solutions, enteral feeds, or food were not collected.

Nursing workload was measured indirectly by the number of infusion adjustments and blood glucose measurements required per patient to reach target blood glucose, and the mean number of dose changes and blood glucose measurements per patient per day. Nurses' satisfaction with the computerized algorithm was assessed by means of an anonymous satisfaction survey that asked about ease of use, glucose control, and overall satisfaction with the Glucommander method. 


\section{Data Analysis}

Data from the control (nomogram) and intervention (Glucommander) groups were compared. Categorical data were analyzed with the $\chi^{2}$ test, and continuous data were compared with the Student $t$ test. A 2-sided $p$ value less than 0.05 was considered statistically significant. Statistical calculations were performed using GraphPad Instat, version 3, and Microsoft Excel, version 9.

Sample size was calculated to detect a $30 \%$ difference in mean amplitude of glucose excursion between the control and intervention groups. To detect this difference with $\alpha=0.05$ and power of $80 \%(B=0.2)$, assuming a coefficient of variation in the mean amplitude of glucose excursion of $20 \%,{ }^{8}$ it was estimated that a minimum of 6 patients would be required in each group. However, because this study was part of a quality assurance audit to evaluate the feasibility of implementing the Glucommander program, it was decided to enrol 50 patients in each group.

\section{RESULTS}

In March and April 2007, 50 consecutive patients admitted to the Cardiovascular Surgery ICU were enrolled in the insulin nomogram (control) group. The Glucommander system was introduced in this ICU in May 2007. Between May and November 2007, patients were enrolled in the Glucommander (intervention) group upon admission to the unit. Patients were identified from the preadmission clinic list and the cardiovascular surgery operating room list before their surgery. Patient recruitment was limited by the availability of researchers to approach patients to obtain their consent and by the availability of patients in the preadmission clinic or on the ward before surgery. None of the patients screened were excluded on the basis of the exclusion criteria. Of the 78 patients who were approached, 50 consented to participate and were enrolled.

Patients' baseline characteristics were well balanced between the 2 study groups (Table 1). There was no significant difference between the 2 groups in terms of mean time to reach target blood glucose $(p=0.39)$ (Table 2). However, mean blood glucose was significantly lower in the Glucommander group than in the control (nomogram) group $(7.9$ versus $8.7 \mathrm{mmol} / \mathrm{L}$, $p=0.002$ ). Although there was no significant difference in the percentage of time within the target range of $5.1-8.0 \mathrm{mmol} / \mathrm{L}$ ( $p=0.37$ ), patients in the Glucommander group spent less time above the target range ( $36 \%$ versus $47 \%, p=0.007)$ and more time below the target range $(11 \%$ versus $3 \%, p<0.001)$. There was no significant difference in the mean amplitude of glucose excursion between the 2 groups $(p=0.27$ ).

Hypoglycemia (blood glucose $<4.0 \mathrm{mmol} / \mathrm{L}$ ) occurred less frequently in the nomogram group (12 [1.4\%] of 875 measurements) than in the Glucommander group (36 [3.7\%] of 973 measurements) ( $p=0.003)$. The administration of dextrose because a patient's blood glucose was below 3.5 $\mathrm{mmol} / \mathrm{L}$ was required twice over a total of 2341 patient-hours in the nomogram group (0.09\%) and 36 times over a total of 2026 patient hours (1.8\%) in the Glucommander group $(p=0.008)$. There were no instances of blood glucose below $2.2 \mathrm{mmol} / \mathrm{L}$, the definition of hypoglycemia used in previous clinical trials, ${ }^{2-6}$ in either group.

The study groups did not differ in terms of the number of infusion adjustments ( $p=0.75$ ) or blood glucose measurements

Table 1. Baseline Characteristics of Study Participants

\begin{tabular}{lccc} 
& \multicolumn{3}{c}{ Group; No. (\%) or Mean \pm SD } \\
\cline { 2 - 4 } Characteristic & $\begin{array}{c}\text { Intervention } \\
\text { Group }(\boldsymbol{n}=\mathbf{5 0})\end{array}$ & $\begin{array}{c}\text { Control } \\
\text { Group }(\boldsymbol{n}=\mathbf{5 0})\end{array}$ & $\mathbf{p}$ value \\
\hline Sex, male & $34(68)$ & $42(84)$ & 0.10 \\
Age (years) & $67.4 \pm 12.0$ & $69.9 \pm 9.9$ & 0.26 \\
Weight (kg) & $79.0 \pm 17.3$ & $82.8 \pm 16.7$ & 0.28 \\
APACHE II score & $13.2 \pm 3.4$ & & $14.2 \pm 4.2$ \\
0.20 & & & \\
Surgical procedure & $35(70)$ & $36(72)$ & $\mathrm{ND}$ \\
Aortocoronary bypass & $4(8)$ & $4(8)$ & $\mathrm{ND}$ \\
Aortic aneurysm repair & $10(20)$ & $7(14)$ & $\mathrm{ND}$ \\
Aortic or mitral valve repair & $1(2)$ & $3(6)$ & $\mathrm{ND}$ \\
Other & $15(30)$ & $22(44)$ & 0.21 \\
History of diabetes & $10.4 \pm 2.0$ & $11.1 \pm 1.9$ & 0.08 \\
Baseline blood glucose* (mmol/L) & $3.3 \pm 6.5$ & $6.5 \pm 12.9$ & 0.13 \\
Length of stay in ICU (days) & $3(6)$ & $3(6)$ & 0.67 \\
Death in ICU & & & \\
APACHE = Acute Physiology and Chronic Health Evaluation II, ICU $=$ intensive care unit, \\
ND = not done, SD = standard deviation. \\
*One patient in each group received corticosteroids & &
\end{tabular}




\section{Table 2. Comparison of Blood Glucose Control}

\begin{tabular}{lccc} 
& \multicolumn{3}{c}{ Group; Mean \pm SD } \\
\cline { 2 - 4 } Characteristic & $\begin{array}{c}\text { Control } \\
\text { Group }(\boldsymbol{n}=\mathbf{5 0})\end{array}$ & $\boldsymbol{p}$ value \\
Group $(\boldsymbol{n}=\mathbf{5 0})$ & \\
\hline Time to target blood glucose* $(\mathrm{h})$ & $6.6 \pm 2.7$ & $7.3 \pm 4.6$ & 0.39 \\
\% time in target range & $53 \pm 19$ & $50 \pm 19$ & 0.37 \\
\% time above target range & $36 \pm 19$ & $47 \pm 19$ & 0.007 \\
\% time below target range & $11 \pm 11$ & $3 \pm 6$ & $<0.001$ \\
Mean insulin infusion rate (units/h) & $3.6 \pm 2.0$ & $2.6 \pm 1.1$ & 0.01 \\
Mean blood glucose (mmol/L) & $7.9 \pm 1.3$ & $8.7 \pm 1.0$ & 0.002 \\
Mean amplitude of glucose excursion & $2.9 \pm 1.7$ & $2.9 \pm 1.9$ & 0.27 \\
\hline *Target range: $5.1-8.0 \mathrm{mmol} / \mathrm{L}$. & & &
\end{tabular}

\section{Table 3. Comparison of Nursing Workload}

\begin{tabular}{|c|c|c|c|}
\hline \multirow[b]{2}{*}{ Characteristic } & \multicolumn{3}{|c|}{ Group; Mean \pm SD } \\
\hline & $\begin{array}{l}\text { Intervention } \\
\text { Group }(n=50)\end{array}$ & $\begin{array}{c}\text { Control } \\
\text { Group }(n=50)\end{array}$ & $p$ value \\
\hline $\begin{array}{l}\text { No. of insulin infusion adjustments } \\
\text { to target }\end{array}$ & $2.9 \pm 2.3$ & $3.0 \pm 3.2$ & 0.75 \\
\hline $\begin{array}{l}\text { No. of blood glucose measurements } \\
\text { to target }\end{array}$ & $4.6 \pm 2.2$ & $4.4 \pm 2.0$ & 0.77 \\
\hline No. of dose changes per day & $10.5 \pm 2.8$ & $4.9 \pm 2.4$ & $<0.001$ \\
\hline $\begin{array}{l}\text { No. of blood glucose measurements } \\
\text { per day }\end{array}$ & $12.0 \pm 2.6$ & $9.8 \pm 2.3$ & $<0.001$ \\
\hline
\end{tabular}

$(p=0.77)$ required to achieve the first reading within the target range (Table 3). However, nursing workload was greater for patients in the Glucommander group, reflected by a significantly greater mean daily number of insulin dose changes required and a significantly greater mean daily number of blood glucose measurements in this group relative to the nomogram group (both $p<0.001$ ).

Qualitative feedback in the form of satisfaction surveys revealed that, overall, the nursing staff preferred the web-based Glucommander system over the nomogram method. In particular, nurses found the Glucommander program somewhat to very easy to use. The overall perception was that the Glucommander program was somewhat to very effective in controlling patients' blood glucose and achieved similar or better glucose control, relative to the nomogram.

\section{DISCUSSION}

This study has demonstrated that the blood glucose levels of postoperative cardiac surgery patients were within target range about $50 \%$ of the time with both the existing paper nomogram used in the Cardiovascular Surgery ICU and the computerized Glucommander system. This result is comparable to those of other studies that have evaluated the use of various insulin nomograms for the management of hyperglycemia. ${ }^{13}$ There was a statistically significant, but clinically small, difference in mean blood glucose between the 2 groups ( 7.9 versus $8.7 \mathrm{mmol} / \mathrm{L})$; the mean value was within the target range of $5.1-8.0 \mathrm{mmol} / \mathrm{L}$ for the Glucommander group but was above range for the nomogram group. This result suggests that the Glucommander method may be slightly more effective in achieving target blood glucose levels than the nomogram, possibly because of aggressive dosing of insulin with the Glucommander method and also because this algorithm adjusts the insulin dose until glucose is within the target range. There was, however, no difference between the groups in the mean amplitude of glucose excursion, a marker of glycemic variability, which suggests that the Glucommander method does not significantly minimize fluctuations in blood glucose. The improved glycemic control may also have reflected the increased extent of monitoring for patients in the Glucommander group.

In this study, hypoglycemic episodes (blood glucose $<4 \mathrm{mmol} / \mathrm{L}$ ) occurred more frequently with the Glucommander system. The continuation of insulin infusion even at low blood glucose levels may have accounted for the apparent increase in the number of blood glucose measurements below $4 \mathrm{mmol} / \mathrm{L}$ and the number of times that dextrose was administered because of blood glucose less than $3.5 \mathrm{mmol} / \mathrm{L}$. As well, glucose levels were checked less frequently with the Glucommander program used in this study, which followed the institution's existing nomogram. By comparison, in the original Glucommander program, ${ }^{7}$ blood glucose measurement is required every $60 \mathrm{~min}$ until glucose control is stabilized and levels have been in the target range for $4 \mathrm{~h}$, at which point the 
interval is increased to a maximum interval as determined by the user. If blood glucose levels drift above the target range, the interval reverts to $60 \mathrm{~min}$. If blood glucose levels are too low, the interval is set to every $30 \mathrm{~min}$. It is not known whether the greater number of episodes of hypoglycemia observed in the Glucommander group in this study was of clinical significance.

Recent trials examining intensive insulin therapy in critically ill patients have also demonstrated a higher incidence of hypoglycemia (blood glucose $<2.2 \mathrm{mmol} / \mathrm{L}$ ), which raises questions about the safety of tight glycemic control..$^{3-6}$ Interestingly, application of this definition of hypoglycemia in the current study did not result in identification of any hypoglycemic episodes. However, the target blood glucose level in this study $(5.1-8 \mathrm{mmol} / \mathrm{L})$ was more liberal than that used in the other trials $(4.4-6.1 \mathrm{mmol} / \mathrm{L})$. Current guidelines for glycemic control now recommend target blood glucose levels of $8-10 \mathrm{mmol} / \mathrm{L}$ for critically ill patients. ${ }^{14}$

Although there was no difference in the number of insulin infusion adjustments or blood glucose measurements required to reach the target blood glucose range, nursing workload was greater in the Glucommander group, as reflected by the greater per-patient frequency of daily insulin dose adjustments and daily blood glucose measurements. The higher frequency of infusion adjustments is not surprising, given that each blood glucose adjustment performed with the Glucommander algorithm is accompanied by a small, incremental change in infusion rate. The greater frequency of blood glucose testing was unexpected, given the identical testing frequency mandated by both methods, but may have been due to an increase in vigilance with the introduction of this new insulin infusion protocol in the Cardiovascular Surgery ICU. In fact, the higher frequency of testing and infusion adjustments may have contributed to the lower mean blood glucose achieved with the Glucommander program.

As with any research, certain limitations were inherent to the structure of this study. The before-after cohort design assumed that the patient population was similar in the 2 periods of the study (before and after introduction of the Glucommander method) and that no other changes in practice occurred during the study period. Patients in the 2 groups were similar in terms of demographic and baseline clinical characteristics. The timing of the 2 arms of the study was such that variability in factors such as unit staffing and practices was minimized. No changes were made in blood glucose targets or policies during the study period.

Because this study was conducted in a cardiovascular surgery ICU at one centre, generalizability to other practice settings, where patients may not be under such close supervision by highly trained nursing staff, is limited. There were also multiple revisions to the Glucommander interface throughout the study period, as part of an ongoing feedback process. These changes may have facilitated use of the program later in the study period and minimized repetition of any errors that were made early on. Because of the small sample size and nonrandomized design, patient-important outcomes (such as wound infections) and costs were not recorded. However, any effects on overall hospital costs through the increase in blood glucose measurements and in administration of D50W with the Glucommander program were most likely negligible.

\section{CONCLUSIONS}

This study demonstrated that the web-based Glucommander program is an effective, easy-to-use tool for tighter blood glucose control. Use of this computerized algorithm improved mean blood glucose levels achieved in the Cardiovascular Surgery ICU relative to the existing insulin nomogram used in that unit. However, the greater frequency of hypoglycemic episodes with the Glucommander program remains a concern. Future improvements in the computerized protocol (e.g., more frequent initial monitoring, alteration of target blood glucose range) may improve safety and efficiency. Despite the increase in nursing workload, nursing staff appeared satisfied overall with the Glucommander program. At the time of writing, widespread implementation of the Glucommander system in the Cardiovascular Surgery ICU had been completed and was being planned for other critical care areas of the institution.

\section{References}

1. Mizock BA. Alterations in fuel metabolism in critical illness: hyperglycemia. Best Pract Res Clin Endocrinol Metab 2001;15(4):533-551.

2. Van den Berghe G, Wouters P, Weekers F, Verwaest C, Bruyninckx F, Schetz $\mathrm{M}$, et al. Intensive insulin therapy in the critically ill patients. $N$ Engl J Med 2001;345(19):1359-1367.

3. Van den Berghe G, Wilmer A, Hermans G, Meersseman W, Wouter PJ, Milants I, et al. Intensive insulin therapy in the medical ICU. $N$ Engl J Med 2006;354(5):449-461.

4. Brunkhorst FM, Engel C, Bloos F, Meier-Hellmann A, Ragaller M, Weiler $\mathrm{N}$, et al. Intensive insulin therapy and pentastarch resuscitation in severe sepsis. N Engl J Med 2008;358(2):125-139.

5. NICE-SUGAR Study Investigators. Intensive versus conventional glucose control in critically ill patients. N Engl J Med 2009;360(12):1283-1297.

6. Griesdale DGE, de Souza RJ, van Dam RM, Heyland DK, Cook DJ, Malhotra A, et al. Intensive insulin therapy and mortality among critically ill patients: a meta-analysis including NICE-SUGAR study data. CMAJ 2009;180(8):821-827.

7. Davidson PC, Steed RD, Bode BW. Glucommander: a computer-directed intravenous insulin system shown to be safe, simple, and effective in 120,618 h of operation. Diabetes Care 2005;28(10):2418-2423.

8. Bode BW, Braithwaite SS, Steed RD, Davidson PC. Intravenous insulin infusion therapy: indications, methods and transition to subcutaneous insulin therapy. Endocr Pract 2004;10 Suppl 2:71-80.

9. Knaus WA, Wagner DP, Draper EA, Zimmerman JE. APACHE II: a severity of disease classification system. Crit Care Med 1985;13(10):818-829.

10. Service FJ, Molnar GD, Rosevear JW, Ackerman E, Gatewood LC, Taylor WF. Mean amplitude of glycemic excursions, a measure of diabetic instability. Diabetes 1970;19(9):644-655. 
11. Egi M, Bellomo R, Stachowski E, French CJ, Hart G. Variability of blood glucose concentration and short-term mortality in critically ill patients. Anaesthesiology 2006;105(2):244-252.

12. Krinsley JS. Glycemic variability: a strong independent predictor of mortality in critically ill patients. Crit Care Med 2008;36(11):3008-3013.

13. Chant C, Wilson G, Friedrich JO. Validation of an insulin infusion nomogram for intensive glucose control in critically ill patients. Pharmacotherapy 2005;25(3):352-359.

14. Moghissi ES, Korytkowski MT, DiNardo M, Einhorn D, Hellman R, Hirsh IB, et al. American Association of Clinical Endocrinologists and American Diabetes Association consensus statement of inpatient glycemic control. Diabetes Care 2009;32(6):1119-1131.

Sharon Yamashita, PharmD, is with the Pharmacy Department, Sunnybrook Health Sciences Centre, Toronto, Ontario.

Emily Ng, BSCPhm, JD, is with McCarthy Tetrault in Toronto, Ontario. At the time the study was performed, she was a resident with the Pharmacy Department, Sunnybrook Health Sciences Centre, Toronto, Ontario.
Frank Brommecker, BScPhm, is with the Pharmacy Department, Sunnybrook Health Sciences Centre, Toronto, Ontario.

Jay Silverberg, MD, is with the Division of Endocrinology, Sunnybrook Health Sciences Centre, Toronto, Ontario.

Neill K J Adhikari, MD, is with the Department of Critical Care Medicine, Sunnybrook Health Sciences Centre, Toronto, Ontario.

\section{Address correspondence to:}

Dr Sharon Yamashita

Pharmacy Department

Sunnybrook Health Sciences Centre

2075 Bayview Avenue

Toronto ON M4N 3M5

e-mail: sharon.yamashita@sunnybrook.ca

\section{Acknowledgement}

The authors would like to acknowledge the nursing staff of the Cardiovascular Surgery Intensive Care Unit for their participation in this study.

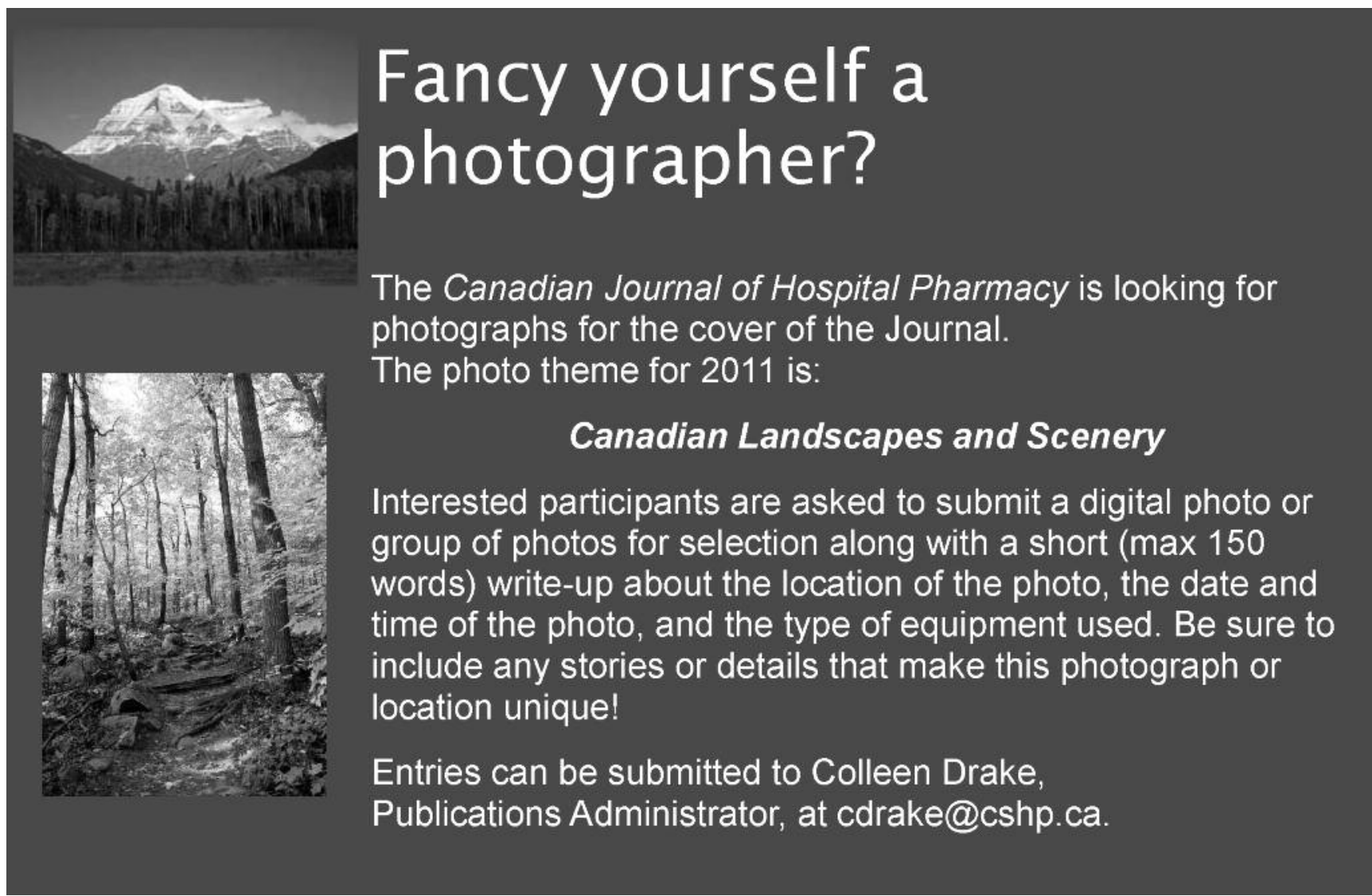

